\title{
BANGUNAN PENJARA DAN PELAKSANAAN PENGHUKUMAN
}

\author{
Praditya Mer Hananto
}

ABSTRACT

All of design in architecture building have some particular composition, compilation and presentation which is exclusively affecting the user inside. Each design have its own world of scope or characteristic which is symbolzed within definition of social relationship. The researcher interested in prison building, a place to implementing a punishment. According to Peter Severin, there is 3 function of prison architecture : confining criminals to protect society, punishing those individuals, and correcting their behavior make them return to society. But the last function is the hardest part and the right design continue to be sought. By studying various literature about prisons architecture design and how punishment implimented, the researcher analyzing pros and cons of each prison design in carrying out the punishment. This research is conducted that each prisons design have its own abilitys, wherein by covering weakness of previously prisons design will resulting in new prison design which is better for implementing punishment. Matter like prisons layout, cels shape, technology, up to materials used was important instrumental to achieving more appropriate design in the effort to reintegarting the convict to society.

Keywords : Confining Those Criminals, Punishing Those Criminals, Correcting Criminals Behaviour

\begin{abstract}
ABSTRAK
Semua desain dalam membangun arsitektur memiliki beberapa komposisi tertentu, kompilasi dan presentasi yang secara eksklusif mempengaruhi pengguna di dalamnya. Setiap desain memiliki lingkup dunia sendiri atau karakteristik yang disimbolisasi dalam definisi hubungan sosial. Peneliti tertarik dengan bangunan lembaga pemasyarakatan, suatu tempat untuk melaksanakan hukuman. Menurut Peter Severin, ada 3 fungsi arsitektur penjara: membatasi penjahat untuk melindungi masyarakat, menghukum orang-orang, dan mengoreksi perilaku mereka membuat mereka kembali ke masyarakat. Namun fungsi terakhir adalah bagian tersulit dan desain yang tepat terus dicari. Dengan mempelajari berbagai literatur tentang desain penjara, arsitektur dan bagaimana hukuman dilaksanakan, peneliti menganalisis dari setiap desain penjara dalam melaksanakan hukuman. Penelitian ini dilakukan terhadap setiap desain penjara memiliki kegunaannya sendiri, dimana dengan menutupi kelemahan sebelumnya desain penjara akan menghasilkan desain penjara baru yang lebih baik untuk menerapkan hukuman. Materi seperti tata letak penjara, bentuk sels, teknologi, hingga bahan yang digunakan adalah penting berperan untuk mencapai desain yang lebih tepat dalam upaya untuk reintegarting narapidana kepada masyarakat.
\end{abstract}

Kata kunci: Membatasi Penjahat, Menghukum Penjahat, Mengoreksi Perilaku Penjahat

\section{PENDAHULUAN}

Desain bangunan dalam bidang arsitektur mempunyai keunikannya sendirisendiri. Untuk mengapresiasinya, oleh Le Corbusier dijelaskan dengan "Kaki yang melangkah, kepala yang menoleh, mata yang melihat". Secara sederhana bisa dikatakan bahwa segala medium yang ada di bangunan arsitektur memiliki komposisi, kompilasi dan presentasi tertentu yang secara khusus mempengaruhi aktifitas fisik penggunanya. Perpustakaan misalnya, adalah ruang dimana segala bentuk teks dikumpulkan bersama dan kurang lebih bisa diakses secara terbuka. Interior perpustakaan membuat orang untuk melangkah melalui barisan rak buku untuk mencapai bagian yang diinginkan, dan kadang menggunakan tangga. Interior perpustakaan memerlukan orang untuk memilih, menarik, memegang buku dan membalik halamannya dalam posisi membaca, sebelum memastikan itulah yang dibutuhkan.

Marcus Vitruvius Pollio (85 - 20 BC) menyatakan bahwa dalam mendesain arstitektural perlu dipikirkan tujuan dari keberadaan akan benda tersebut, dan ia secara 
garis besar membaginya menjadi : bangunan publik, semi-publik, dan privat, yang mana tiap wilayah memiliki desain maupun tujuannya masing-masing. Dikombinasikan dengan Erving Goofman mempopulerkan istilah Total Institution, dimanatiap institusi memiliki sesuatu yang meliputi minat dari anggotanya dan memberikan suatu layanan pada dunia mereka. Singkatnya, tiap institusi memiliki “dunianya" sendiri (Burns, 1992). Cakupan atau karakteristik mereka disimbolkan dalam batasbatas hubungan sosial, dimana untuk tampilan luar nya bisa berciri seperti : pintu yang terkunci, dinding tinggi, kawat berduri, keterbukaan, warna dan sebagainya. Dalam hubungannya dengan ranah kriminologi, maka peneliti akan mulai dari desain bangunan dalam bidang penegakan hukum.

Ketika melihat berbagai desain bangunan di bidang penegakan hukum, peneliti melihat bagaimana ada begitu banyak ragam tampilan di luar dan di dalam bangunan tersebut, yang mana tampilan bangunanbangunan itu tentunya disengaja dengan maksud dan tujuan tertentu. Maka, bangunan yang menarik perhatian peneliti adalah bangunan penjara yang merupakan tempat bangunan untuk melakukan penghukuman.

\section{Sejarah Bangunan Penjara dan \\ Penghukuman}

Awalnya, "pemenjaraan" lebih sering digunakan sebagai penahanan sementara sebelum tahanan dihukum mati atau dijadikan budak, sehingga penjara itu sendiri sebenarnya tidak dijadikan cara untuk menghukum. Tapi dengan berlalunya waktu dan majunya peradaban, penjara mulai bermetamorfosis menjadi correctional facility yang menjalankan konsep merehabilitasi dan membentuk ulang tahanan (Colvin, 1997). Salah satu catatan awal keberadaan penjara berasal dari 3000 tahun SM di peradaban Mesopotamia dan Egypt, dimana di masa tersebut penjara hampir selalu berada di ruang bawah tanah ( Muchou, 2005). Tujuan dalam melakukan penahanan sendiri terus berevolusi sesuai dengan filosofi dalam penghukuman yang terus berkembang dalam masyarakat. Hal ini pada akhirnya banyak dipengaruhi dan mempengaruhi bentuk ruang, atau bangunan, tempat penghukuman dilakukan ( Rhodes, 2004 ).

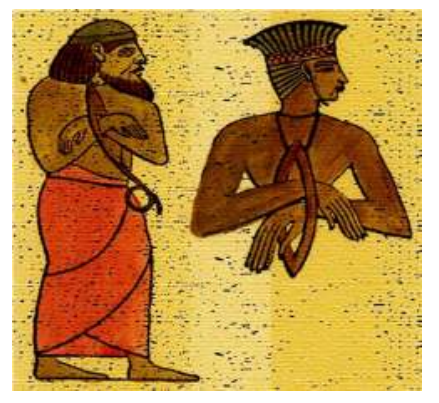

Gbr 1. Ilustrasi bentuk penahanan awal, dimana terhukum hanya sekedar dikekang. Sumber :www.visualbiblealive.com

Pada tahun 1777, John Howard berkeliling eropa dan melihat bobroknya kondisi penjara. Ia mengutuk penjara yang tak terorganisir, barbar dan dekil. Ia pun mengajukan perubahan termasuk pemisahan napi pria, wanita, anakanak, memasukkan karyawan yang dibayar, inspeksi luar, sanitasi, kebutuhan gizi, kesehatan dan hal-hal lain yang diperlukan tahanan 
(McShane \& Williams, 2005). Jeremy Bentham dan para perubah sistem hukuman pada masa itu, juga percaya bahwa tahanan seharusnya cukup menderita, tapi hal tersebut haruslah tidak merusak kesehatan tahanan. Mereka juga meminta pemisahan pria dengan wanita, dan peningkatan sanitasi. Tahun 1791 Bentham mendesain "panopticon", dimana desain penjara ini membuat para pengawas menjadi terpusat dalam mengawasi para tahanan dari tengahtengah penjara,. Pada tahun 1799, Penitentary Act di Inggris secara spesifik menyatakan bahwa di dalam penjara harus dibuat sistem satu sel satu tahanan dan mengaplikasikan silent system saat sedang bekerja (Colvin, 1997).

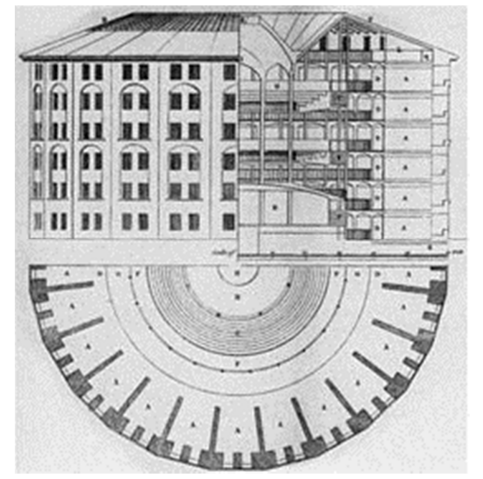

Gbr 2. Konsep penjara panopticon. Prinsip pejagaannya adalah dengan mengawasi sel-sel tahanan dari bagian dalam bangunan itu sendiri. Berbeda dengan bangunan penjara sebelum ini,dimana konsepnya mengawasi dari sisi luar bangunan. Sumber : www.panopticongallery.com

Jaman penjara modern di masa sekarang diawali dengan perubahan beberapa penjara pada abad 19 di Inggris. Pada periode tersebut para tahanan mulai mendapat perlakuan lebih baik, konsep rehabilitasi mulai dikenalkan dan pemerintah dunia mulaimempertimbangkan pandangan mereka tentang pengurungan terpencil, yang merupakan sumber meningkatnya jumlah tahanan tidak waras, bunuh diri dan kondisi catatonic. Grup religius seperti Quakers dan Evangelicals sangat berpengaruh dalam menyuarakan ide reform penjara melalui penyelamatan individu (McShane \&Williams, 2005). Penitentiary (salah satu jenis penjara dengan konsep penyesalan diri)nasional pertama selesai dibangun di Millbank di London tahun 1816. Disana ada 860 tahanan, terpisah per sel, dimana asosiasi antar tahanan diijinkan di siang hari. Pekerjaan di penjara hanya berkisar seperti mencari serabut kelapa dan menenun. Tahun 1842 dibuatlah penjara Pentonville dengan desain panopticon. Penjara tersebut di desain untuk 520 orang, masing-masing dengan sel sepanjang 13 kaki, lebar 7 kaki, tinggi 9 kaki, dengan sistem solitary confinement. Tahun 1877 penjara dikontrol oleh Prison Comission, dimana untuk pertama kalinya penjara lokal dikontrol secara terpusat. Pada saat itu penjara dilihat sebagai ancaman untuk menggentarjerakan pelanggar dan residivis. Tahun 1898 muncul Prison Act yang merupakan cikal bakal kebijakan penjara sekarang, yang menekankan bahwa pekerjaan yang dilakukan tahanan haruslah produktif, sehingga bisa menghidupi diri mereka setelah dilepaskan (Banks, 2005). 
Hingga muncul The Criminal Justice Act tahun 1948 yang menghilangkan sistem kerja paksa, kerja keras dan pencambukan. UU tersebut juga menghadirkan sistem lebih tepat untuk melakukan penghukuman dan memperlakukan tahanan. Begitu pula dengan keberadaan United Nation's Standard Minimum Rules (SMR) untuk perlakuan terhadap narapidana yang diangkat pertama kali tahun 1955 oleh majelis umum PBB dalam Mencegah Kejahatan dan Perlakuan terhadap Pelanggar di Jenewa, yang kemudian disetujui oleh Dewan

Ekonomi dan Sosial dalam resolusi 31 Juli 1957 dan 13 Mei 1977. Walau tidak sepenuhnya mengikat, standar ini memberi petunjuk bagi hukum Internasional maupun domestik dalam menangani orang yang ( akan ) ditahan dipenjara maupun bentuk penahanan lain. Yang mana dalam hal ini secara umum disetujui sebagai dasar prinsip dan praktek yang baik dalam memperlakukan narapidana dan mengatur lembaga penjara sehingga mempengaruhi desain yang dibutuhkan.

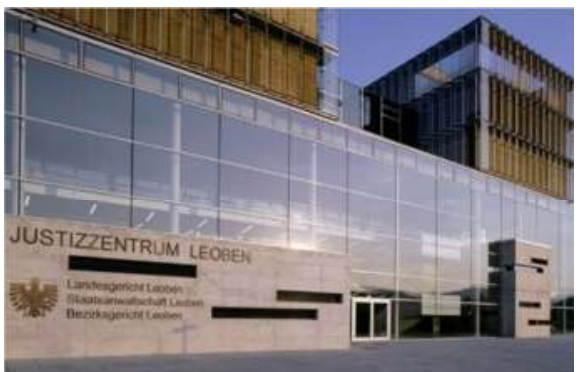

Gbr 3. Leoben Justice and Detention Center, Austria. Salah satu penjara yang tidak dibuat seperti penjara pada umumnya yang berkesan abu-abu. Sumber :

http://www.mimoa.eu/projects/Austria/Leoben/Justice\%20and\%20Detention\%20Centre

Jika pada awal mula tujuan melakukan penghukuman dengan pengekangan adalah sebagai balas dendam, maka sejalan dengan makin berkembangnya pola pemikiran masyarakat modern, kini tujuan dari pemenjaraan adalah untuk mengintegrasikan para pelanggar kembali ke masyarakat. Di Indonesia, gagasan pemasyarakatan dicetuskan pertama kali oleh Dr. Sahardjo, SH. pada tanggal 5 Juli 1963 dalam pidato penganugerahan Doktor Honoris Causa di bidang Ilmu Hukum oleh Universitas Indonesia (Sujatno, 2008). Pada tanggal 27 april 1964 dalam konferensi dinas Direktorat Pemasyarakatan di Lembang Bandung, gagasan tersebut diformulasikan sehingga istilah penjara menjadi Lembaga Pemasyarakatan, sistem pemenjaraan diganti menjadi sistem pembinaan, dan kata napi dirubah menjadi Warga Binaan (WB), dengan dasar pembinaan yang disebut “Sepuluh Prinsip Pemasyarakatan”. Jadi, fungsi dari penjara bukan hanya sekedar untuk memenjarakan, melainkan mempunyai tugas yang lebih berat, yaitu mengembalikan orangorang yang dijatuhi pidana ke dalam masyarakat.

\section{TINJAUAN TEORITIS}

Menurut Peter Severin, Chief Executive untuk SA Corrective Service dalam Prison and Correctional Facilities Asia 2012, bahwa pada dasarnya ada 3 fungsi dari sebuah arsitektur penjara (prisondesign.org). Pertama, untuk menaruh (dan mengumpulkan) para kriminal untuk melindungi masyarakat dari 
bahaya kedepannya. Kedua, menghukum individu-individu tersebut sebagai akibat dari perilakunya. Ketiga, untuk memperbaiki perilaku mereka sehingga mereka bisa kembali ke masyarakat sebagai orang yang taat hukum. Tapi pada prakteknya, hanya fungsi pertama dan kedua lah yang cenderung menjadi acuan dalam membuat sebuah bangunan penjara. Fungsi ketiga adalah fungsi yang dianggap paling sulit untuk dilakukan, sehingga desain yang tepat terus dicari.

\section{Menurut Peter Severin, Chief} Executive untuk SA Corrective Service dalam Prison and Correctional Facilities Asia 2012, bahwa pada dasarnya ada 3 fungsi dari sebuah arsitektur penjara (prisondesign.org). Pertama, untuk menaruh (dan mengumpulkan) para kriminal untuk melindungi masyarakat dari bahaya kedepannya. Kedua, menghukum individu-individu tersebut sebagai akibat dari perilakunya. Ketiga, untuk memperbaiki perilaku mereka sehingga mereka bisa kembali ke masyarakat sebagai orang yang taat hukum. Tapi pada prakteknya, hanya fungsi pertama dan kedua lah yang cenderung menjadi acuan dalam membuat sebuah bangunan penjara. Fungsi ketiga adalah fungsi yang dianggap paling sulit untuk dilakukan, sehingga desain yang tepat terus dicari.

Dalam mendesain sebuah bangunan, tentunya perlu memahami untuk apa / siapa bangunan itu ada, dan juga memperkirakan perilaku dari para penghuninya sehingga bisa mengerti apa saja yang perlu ada dan apa saja yang tidak (Hale, 2000). Maka dengan memahami kondisi yang akan dihadapi oleh penghuni penjara, seperti napi, petugas dan pengunjung, maka kita bisa membuat kehidupan penjara lebih mudah baik bagi napi maupun mereka yang bekerja disana. Christian NorbergSchulz (1980) memberi 4 jawaban atas pertanyaan tugas sebuah bangunan. Salah satunya adalah Functional Frame yang banyak membahas aspek-aspek fisik perilaku manusia. Pada dasarnya manusia selalu melakukan kegiatan, sehingga membutuhkan wadah arsitektural untuk menampung kegiatan tersebut. Ia menyatakan bahwa walau fungsi bangunan tetap sama, suasana yang ada bisa berubah seiring dengan berjalannya sejarah. Berikutnya adalah yang disebut Expressive Function oleh Jan Mukarovsky (1936) sebagai bentuk penekanan terhadap bermacam-macam aspek identitas melalui isyarat-isyarat atau penanda yang diberikan pada bangunannya. Isyarat itu diterjemahkan kedalam seni arsitektur sebagai pembeda fungsi dari bangunan yang ada. Isyarat tersebut melibatkan detail geometri atau bentuk-bentuk spatial, penggunaan material, warna tekstur dan sebagainya. Begitu pula dengan Territorial Function, yang digunakan sebagai pembeda fungsi ruang dengan tanda penulisan misalnya (Harrison \& Wood, 1992). Hal itu disambung oleh Larry L. Ligo (1984) dalam Psychological Function, yang mengacu pada kondisi perasaan yang dirasakan manusia dimana bangunan tersebut berbaur dengan pengamatpengamatnya, penghuninya, termasuk penyakitpenyakit psikologis seperti vertigo, claustrophobia, kebingungan arah, kenyamanan fisik hingga kurangnya rasa dan emosi yang spesifik. Selain itu juga ada Social Function, yang mengacu pada ketegasan dari institusi sosial dan karakteristik nya (Harrison \& Wood, 1992). Dan dengan salah satu dari konsep Total Institution dari Erving Goffman (Burns, 1992), yaitu tempat yang diorganisir untuk melindungi masyarakat dari sesuatu yang dianggap membahayakan, yang mana salah satunya adalah penjara sebagai tempat untuk 
melaksanakan penghukuman. Tempat di mana semua aspek kehidupan berlangsung di tempat tersebut tdan di bawah satu otoritas yang sama. Tempat di mana aktivitas tiap penghuninya dilakukan bersama, melakukan hal yang sama dan semuanya diperlakukan sama. Tempat di mana segala aktivitas mempunyai jadwal yang ketat, dimana aktivitas yang satu merupakan persiapan aktivitas berikutnya, dan seluruh kegiatan ditentukan dari atas melalui sistem, aturan yang jelas dan resmi. Dan tempat di mana segala aktivitas yang dipaksakan secara keseluruhan bertujuan untuk mencapai tujuan dari institusi tersebut. Maka diperlukan desain yang tepat untuk mencapai tujuan-tujuan itu.

Untuk mengurangi masalah dalam penjara, maka diperlukan desain dengan tujuan mencegah kejahatan yang bertujuan untuk mengurangi kesempatan kriminal, jadi bukan untuk menyerang niat kriminal itu sendiri. Hal ini berdasarkan alasan bahwa dengan mengurangi kesempatan kriminal (seperti membuat target tidak terakses, ataupun jika kriminal terjadi justru membahayakan pelakunya sendiri), merupakan pendekatan yang bisa dilakukan dan terbukti bermanfaat (National Crime Prevention Institute, 2001). Maka desain ruang yang benar juga bisa mengurangi kemungkinan terjadi berbagai situasi yang tidak diinginkan (atau diinginkan) di dalam penjara. Menurut Todd S Philips dan Michael A Griebel, ada 5 fungsi desain bangunan penjara (Ardoko, 2014 ) :

1. Deter (Halangi). Menekankan fungsi dan pencegahan / penghalangan terhadap kemungkinan potensi gangguan pelarian / perusakan dan penyalahgunaan fungsi bangunan. Misalnya berupa pagar dan tembok pengaman.
2. Detect (Deteksi). Menekankan pada fungsi kemudahan pengawasan dan pemantauan untuk mengetahui sedini mungkin adanya gangguan keamanan.Misalnya : pos pengamanan, menara, ruang control.

3. Delay (Tunda). Menekankan pada fungsi pengaturan dan penghambatan terhadap aksesibilitas sebagai upaya penghambatan/memperpelan terhadap gangguan. Misalnya : penataan pintu, penghambatan akses antar ruang.

4. Halt (Hentikan): Menekankan paada fungsi kontrol dan kendali pada saat dimulai/ sedang terjadinya kemungkinan penyimpangan. Misal : ruang2 jebakan, steril, isolasi, dll.

5. Minimize (Perkecil) : Menekankan pada fungsi mengurangi/meminimalisir kerusakan yang terjadi ketika ada kejadian. Misal: penggunaan teknologi dan material bangunan serta detail bangunan yang didesain khusus.

Untuk memperoleh semua itu, perancang juga harus tahu ukuran, alat-alat, pakaian dan sebagainya yang ada di sekitar manusia untuk dapat menentukan besarnya tempat dan mebel yang sesuai. Begitu juga dengan tempat yang dibutuhkan manusia dalam sebuah ruangan agar pekerjaan yang dilakukan bisa menjadi lebih mudah, dan nyaman (Neufert, 1996). Maka digunakanlah teori ergonomi yang dirumuskan sebagai "teknologi perancangan kerja" yang "didasarkan pada ilmu-ilmu biologi manusia, anatomi, fisiologi dan psikologi”. Jadi secara sederhana disebut sebagai "ilmu antar disiplin yang mempelajari hubungan-hubungan antara manusia dan lingkungannya" (Panero \& Zelnik, 2003). 

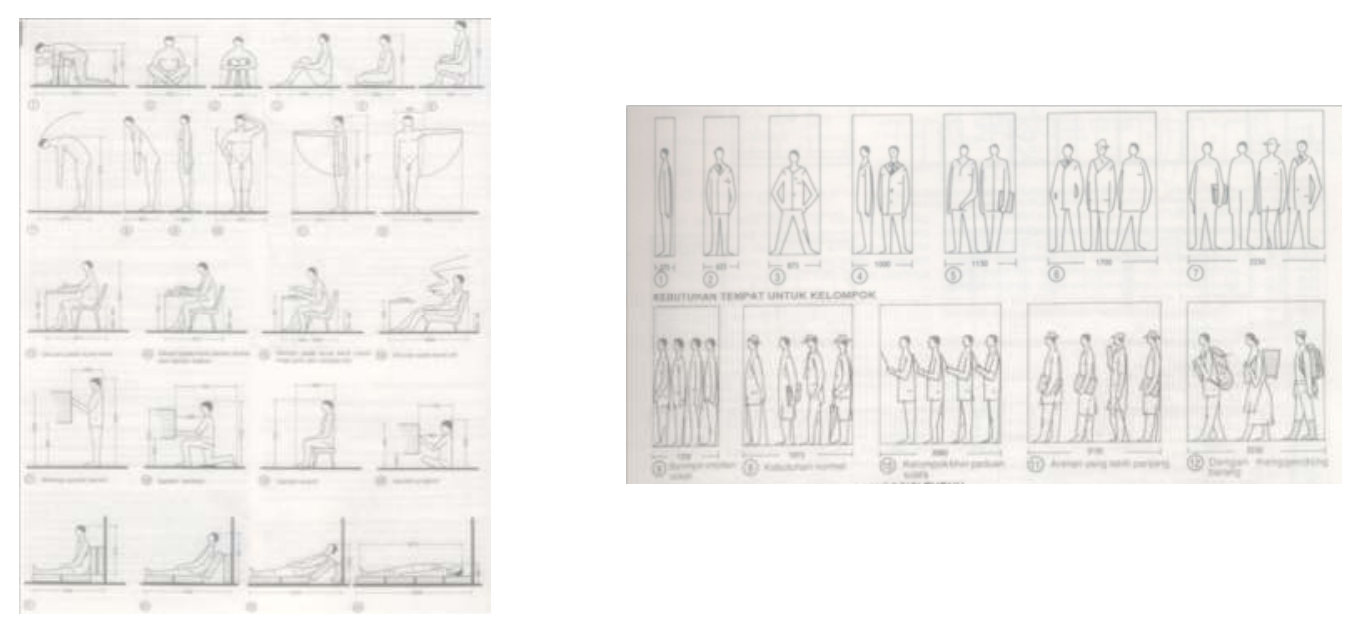

Gbr 4.( Kiri ) :Rata-rata ukuran tubuh manusia dalam bergerak. ( Kanan ) : Kebutuhan rata-rata tempat diantara dinding untuk pergerakan manusia. Sumber :Neufert ( 1996 ).

Desain layout penjara juga memegang peranan penting dalam mencapai tujuan ini. Howard B. Gill, adalah seorang Direktur dari Institute of Correctional Administration di Universitas Amerika. Dalam Correctional Philosophy and Architecture (1962), ia menggambarkan 10 susunan layout penjara sebelum tahun 1962 (gambar 2-14). Tapi pada sumber-sumber yang lebih baru, layout desain penjara hanya menyebutkan 3 jenis (gambar 213): Telephone Pole Design, Campus Design, dan campuran / bukan keduanya (Bosworth, 2005 ; McShane \& Williams, 2005 ; Morris \& Worral, 2010). Hal itu dikarenakan variasi desain arsitektural sendiri begitu banyak ragamnya, sehingga akan menyulitkan jika dikelompokkan secara sangat spesifik

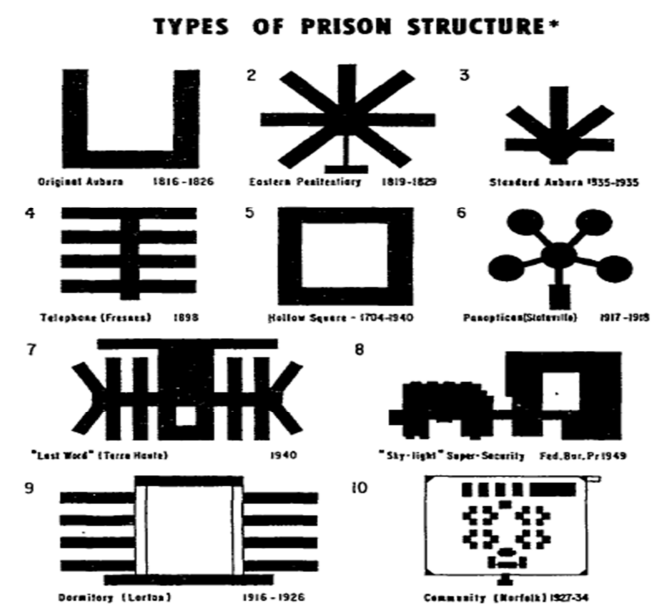

Gbr 5.Layout berbagai penjara sebelum tahun 1962. Sumber : Gill, 1962.

Secara perkembangan desain sendiri menurut Kriminolog Inggris Roy King, arsitektural penjara di Barat sebenarnya berkembang dibagi menjadi 3 tahap. Tahap pertama, ialah penjara yang dibuat berjejer seperti kurungan, bertingkat-tingkat, dan sebentar-sebentar dilalui oleh sipir penjara. Penjara generasi pertama ini cenderung meniru tampilan benterng, terutama 
dalam menunjukkan ukuran dan sekalanya yang besar, menonjolkan bagian gerbang dan penjagaan menaranya (dalam arti persenjataannya, entah orang yang mebawa senapan ataupun keberadaan senapan mesin). Intinya, dengan menunjukkan kesan kastil akan memberikan kesan bahwa "ini adalah penjara". Untuk penjara generasi kedua, secara gaya arsitektural hampir tidak berbeda dengan generasi awal. Tetapi generasi ini mengurangi jumlah penjaga manusia yang berkeliling, dan menggantinya dengan kamera video. Pada era yang baru, penjara pada dasarnya didesain untuk sesuai dengan struktur, landscape, atau bahkan dibuat seperti kampus ataupun perkantoran. Pengaturan tata letak bangunan di penjara baru cenderung meminjam desain Panopticon nya Bentham, yaitu keberadaan pusat pengawaspengontrol yang dikeliling berbagai bangunan yang diawasi, yaitu sel para napi. Para napi juga biasanya hidup di sel yang dibuat sesuai dengan building code. Antara sel napi dengan pusat pengawas biasa dipisahkan oleh kaca anti pecah, dan kadang kaca satu arah, atau dibuat menyerupai itu.

\section{METODE}

Saya sebagai peneliti memilih penggunaan studi literatur dalam melakukan penelitian ini. Menurut Ian Holder, studi literatur merupakan studi yang melakukan interpretasi terhadap bukti bisu seperti teks tertulis ataupun artefak (Denzin \& Lincoln, 1998). Alasan pemilihan studi literatur, adalah karena secara umum lebih mudah di akses dan

\section{TEMUAN}

Desain Panopticon cenderung menjadi rujukan dalam berbagai buku yang membahas mengenai penjara, dikarenakan filosofi desain ini dianggap sebagai pionir dalam melakukan rendah biaya, juga informasi yang diberikan bisa berbeda dan bisa tidak ada dalam bentuk percakapan, dan juga karena literatur mempunyai daya tahan sehingga bisa memberi gambaran historis (Denzin \& Lincoln, 1998). Buku, jurnal dan penelitian akademik dianggap sebagai literatur yang relevan. Sebab kedua literatur tersebut merupakan jenis literatur akademik, yang berarti untuk proses supaya dipublikasikan perlu adanya penyaringan untuk memastikan kesesuaian dan ketepatan isinya. Jika literatur seperti buku, jurnal atau penelitian cenderung untuk kalangan akademik, maka media cetak, web site ( entah itu situs .gov / .org / .com dsb) ada kecenderungan untuk supaya dikonsumsi masyarakat umum. Walau literatur majalah tujuanya untuk profit, tapi isi dari media yang memang kompeten tentunya memiliki bobot nya sendiri, misal dengan adanya review-review dari para pakar yang memang di bidangnya. Sedangkan untuk web site jika dilakukan oleh pihak pemerintah ataupun organisasi hingga akademisi (yang memiliki akhiran seperti gov, org, ac, edu dll), tentu nya juga mempunyai bobot nya sendiri. Untuk memperoleh data tambahan literatur penjara di Indonesia, saya melakukan diskusi tatap muka dengan Ir. Purwo Ardoko, yang merupakan narasumber utama dalam desain arsitektur penjara di Indonesia. Inti dari diskusi adalah tentunya bagaimana arsitekturpenjara di Indonesia disesuaikan dengan kondisi iklim, budaya dan hukum yang berlaku.

pelaksanaan hukuman (Banks, 2005 ; Bosworth, 2005 ; Colvin, 1997 ; Kepos, 2008 ; Logan, 1990 ; McShane \& Williams, 2005). Tetapi sebelum ada panopticon, tentunya ada penjarapenjara yang dianggap tidak tepat dijadikan 
pionir desain penjara, tetapi keberadaannya

tidak bisa diabaikkan begitu saja. Sebab Bentham sendiri mendapatkan konsep panopticon juga karena melihat adanya kekurangan dari penjara-penjara yang ada sebelumnya (Bozovic, 1995). Dengan demikian, maka hasil penemuan sejatinya akan diawali pembahasannya pada penjara-penjara di Pensylvania yang dianggap sebagai desain awal dari penjara generasi pertama (Wortley, 2004), dan sekaligus sebagai titik terawal sejarah perkembangan penjara di Amerika (Banks, 2002 ; Colvin, 1997 ; NcShane \& Williams, 2005 ; www.pci.state.pa.us/portal/server.pt/community / history_of_pci/17812).

Tapi jika ditelusuri lagi ke masa lalu, peneliti menemukan bahwa desain generasi pertama yang berbentuk seperti kastil, memang berasal dari kastil yang ditinggalkan untuk kemudian dialih fungsikan menjadi penjara (Leppage, 2002), dimana awal (maupun asal kata) dari kastil itu sendiri, berasal dari tembok pertahan yang dibangun oleh Kerajaan Romawi
Kuno menjelang akhir kejayaannya (Stokstad, 2009). Salah satu bangunan peninggalan kejayaan Romawi yang bisa dilihat hingga sekarang, adalah Colosseum, yang sebenarnya merupakan salah satu tempat seorang "kriminal" dihukum (Malam, 2004 ; Nossov, 2009 ; Wisdom, 2001). Lebih lanjut, jika berdasarkan Muchou Poo (2005), peneliti tidak menemukan keterangan mengenai bangunan yang khusus dibuat untuk menampung para kriminal saja. Berdasarkan intepretasi tersebut maka peneliti memilih bangunan "sekolah gladiator", yang merupakan bangunan yang dibuat khusus untuk menahan dan melatih para gladiator (yang sebenarnya adalah para tawanan walau ada sebagian kecil yang merupakan sukarelawan) sebelum "dihukum", bisa dijadikan sebagai pembuka untuk mengawali tulisan temuan mengenai desain penjara, dan pelaksanaan penghukumannya.

Tabel 1. Hasil Penelitian

\begin{tabular}{|l|l|}
\hline \multicolumn{1}{|c|}{ Penjara } & \multicolumn{1}{c|}{ Penjelasan } \\
\hline & $\begin{array}{l}\text { Di peradaban inilah pertama kali ditemukan penjara yang berbentuk } \\
\text { kompleks. Ludus gladiatorius (sekolah gladiator) sebenarnya merupakan } \\
\text { "penjara" untuk para kriminalnya. Hal ini karena tidak ada peradaban lebih } \\
\text { tua dari Romawi yang memiliki sistem kompleks penjara. (Muchou Poo, } \\
\text { 2005). }\end{array}$ \\
$\begin{array}{l}\text { Sekolah } \\
\text { Kladiator Era } \\
\text { Rokaisaran } \\
\text { SM ). }\end{array}$ & $\begin{array}{l}\text { Memiliki layout bangunan Hollow Square, salah satu formasi infantri } \\
\text { Romawi dengan tujuan merebut bagian tengah (McNab, 2010), dengan desain } \\
\text { sel linear. Menekankan pada pengawasan. }\end{array}$ \\
& $\begin{array}{l}\text { Proses awal pelaksanaan hukuman, adalah melatih para kriminal menjadi } \\
\text { gladiator. Eksekusi hukumannya, adalah mengadu gladiator dengan gladiator } \\
\text { lain di amphitheatre. Karena sekolah yang memiliki gladiator pemenang akan } \\
\text { terangkat namanya, maka para gladiator itu dilatih berbagai hal, terutama cara } \\
\text { bertarung. Gladiator yang terus menang, bisa memperoleh kebebasannya. }\end{array}$ \\
\hline
\end{tabular}




\begin{tabular}{|c|c|}
\hline Penjara & Penjelasan \\
\hline & (Fields, 2009 ; Malam, 2004 ; Nossov, 2009; Wisdom, 2001). \\
\hline $\begin{array}{l}\text { Model Kastil } \\
\text { Medieval di } \\
\text { Eropa (5 - } \\
\text { 15M). }\end{array}$ & $\begin{array}{l}\text { Langsung melompat ke abad } 14 \text { dimana berkat penemuan bubuk mesiu, } \\
\text { menyebabkan hampir semua kastil ditinggalkan karena sudah tidak mampu } \\
\text { menahan daya rusak berbagai peralatan artileri (Lepage, 2012). } \\
\text { Kastil pada akhirnya difungsikan sebagai "kompleks" penjara (setelah tidak } \\
\text { lagi digunakan sebaga hunian) karena sebuah kastil pada dasarnya didesain } \\
\text { sebagai bangunan pertahanan yang melindungi pemerintah dan sebagai tempat } \\
\text { "teraman" terakhir untuk berlindung ketika serangan yang terjadi berhasil } \\
\text { menembus tembok pertahanan kota (Lepage, 2002). } \\
\text { Tiap desain dalam sebuah kastil selalu mempunyai fungsi untuk bertahan } \\
\text { maupun menyerang. Terutama karena di abad } 7 \text { hingga } 12 \text { di Eropa perang } \\
\text { Islam dengan Kristen begitu berkecamuk, sehingga kastil (dan juga strategi) } \\
\text { terus mengalami peningkatan (Stokstad, 2009). Tetapi pada kastil, fungsi } \\
\text { pertahanan lebih ditingkatkan daripada fungsi penyerangan. Penguasaan } \\
\text { bangsa Arab berakhir di berbagai wilayah Eropa pada 1492, disebut sangat } \\
\text { mempengaruhi penguatan fugsi pertahanan pada kastil. Fungsi pertahanan } \\
\text { yang dimaksud seperti seperti donjon (menara pengawas), penggunaan } \\
\text { campuran yang disebut tapia untuk merekatkan batu di tembok lalu } \\
\text { dikeringkan oleh matahari, dan juga berbagai upaya dalam menghilangkan } \\
\text { beberapa titik buta ketika mengawasi area luar kastil. (Leppage, 2002). Sebab } \\
\text { pada kenyataannya untuk menyerang (merebut) sebuah kastil sangatlah } \\
\text { membutuhkan biaya tinggi, yang mana berarti desain kastil sebagai } \\
\text { pertahanan sudah begitu diakui ( Hull, 2006). }\end{array}$ \\
\hline $\begin{array}{l}\text { Era Quaker dan } \\
\text { Moderate }\end{array}$ & $\begin{array}{l}\text { Utamanya, adalah bagaimana pemikiran golongan Quaker dan Moderate } \\
\text { Light, dimana golongan pertama (religius) yakin bahwa hukuman penyesalan } \\
\text { adalah cara }\end{array}$ \\
\hline Light & $\begin{array}{l}\text { untuk mengurangi tingkat kejahatan, sedangkan golongan kedua ( rasionalis ) } \\
\text { yakin bahwa disiplin diri merupakan kunci produktivitas yang akhirnya } \\
\text { menurunkan tingkat kejahatan (Banks, } 2005 \text {; Colvin, } 1997 \text {; Foucaut, } 1977 \text {; } \\
\text { McShane \& Williams, } 2005 \text {; Peterson 1953). }\end{array}$ \\
\hline $\begin{array}{l}\text { Walnut Street } \\
\text { Jail, } \\
\text { Philadelhia } \\
\text { ( } 1773 \text { ). }\end{array}$ & $\begin{array}{l}\text { Merupakan penjara pertama di Amerika (dan di dunia) yang memadukan } \\
\text { filosofi penologi Quaker dan arsitektur, juga merupakan penjara pertama yang } \\
\text { menggunakan sistem sel individu. (Bosworth, 2005; McShane \& Williams, } \\
\text { 2005, Peterson 1953). Sisi exterior didesain "biasa", sehingga mereka (para } \\
\text { narapidana) yang tinggal di bangunan tersebut seolah tidak berbeda dengan } \\
\text { mereka (penduduk baik-baik) yang tinggal di bangunan-bangunan sekitarnya } \\
\text { karena ekspresi bangunan ini bisa menyatu dengan lingkungannya } \\
\text { (Broadbent, } 1973 \text {; Ligo, } 1984 \text {; Mukarovsky 1936). } \\
\text { Pelaksanaan hukuman di tempat ini memaksa napi untuk bersikap produktif } \\
\text { seperti menanam buah dan sayuran, dan memproduksi barang. } \\
\text { Awal kegagalan desain penjara ini terjadi pada sekitar abad 18. Walau pada }\end{array}$ \\
\hline
\end{tabular}




\begin{tabular}{|c|c|}
\hline Penjara & Penjelasan \\
\hline & $\begin{array}{l}\text { awalnya sel isolasi dibuat untuk "pelanggar kejahatan berat", sebuah } \\
\text { peraturan pada } 1794 \text { menyatakan bahwa semua pelaku kriminal harus } \\
\text { menjalani hukuman sel isolasi ( Bosworth, 2005). }\end{array}$ \\
\hline $\begin{array}{l}\text { Newgate Prion, } \\
\text { New York di } \\
\text { masa } \\
\text { kepemimpinan } \\
\text { Thomas Eddy ( } \\
1797 \text { ). }\end{array}$ & $\begin{array}{l}\text { Desain luar ala kastil, dengan pembagian konsep kriminal berdasarkan } 3 \\
\text { jenis : wanita di kanan, pria di tengah dan para penghutang di kiri. Tiap blok } \\
\text { memiliki hall nya sendiri-sendiri, sehingga masing-masing blok bisa } \\
\text { berativitas tanpa saling bersentuhan. Konsep desain modular memungkinkan } \\
\text { menutup blok ketika terjadi kerusuhan sehingga tidak sampai mempengaruhi } \\
\text { kondisi blok yang lain. Disebut architecture terrible oleh arsitek Perancis } \\
\text { Jacques-Francois Bondel (Harrison \& Woods, 1992). } \\
\text { Melarang pemukulan terhadap napi berkat keberhasilan Eddy mensahkan } \\
\text { undang-undang untuk melarang hukuman fisik di penjara. Hukuman terberat } \\
\text { bagi perilaku yang buruk adalah penambahan waktu isolasi dan pengurangan } \\
\text { jatah makan. Sistem kerja di Walnut Street Jail dan Newgate cukup mirip } \\
\text { (Bosworth, 2005). } \\
\text { Kegagalan penjara ini diakibatkan karena mudahnya napi bergerombol, } \\
\text { berjudi, menuju bar, dan diijinkan menukar ransum mereka, mengakibatkan } \\
\text { kerusuhan dan kabur merupakan hal yang sering terjadi. Penjara ini gagal (dan } \\
\text { dibubarkan) bukan karena overcrowded, melainkan karena lingkungan penjara } \\
\text { yang melahirkan "kekerasan, kerusuhan, huru-hara, sifat buruk dan kejahatan" } \\
\text { dan menjadi sekolah kejahatan (Bosworth, 2005). }\end{array}$ \\
\hline Panopticon & $\begin{array}{l}\text { Memberi kesan bahwa napi diawasi. Sipir bisa melihat (mengawasi ) napi } \\
\text { dari pos jaga ditengah yang dipasang venetian blind (kerai), sementara napi } \\
\text { tidak bisa melihat kondisi sipir. }\end{array}$ \\
\hline $\begin{array}{l}\text { Eastern State } \\
\text { Penitentiary } \\
\text { (1829). }\end{array}$ & $\begin{array}{l}\text { Merupakan acuan penjara terbaik yang benar-benar menggabungkan desain } \\
\text { arsitektur dengan konsep religius nya Quaker dan rasionalis nya Moderate } \\
\text { Light dalam melakukan penghukuman. Bangunan pertama yang } \\
\text { menggunakan sistem pumbling. } \\
\text { Napi diberi pelatihan dan dipekerjakan sebagai proses pelaksanaan } \\
\text { penghukuman. } \\
\text { Awal "Kegagalan" sistem ESP dimulai pada tahun 1819, ketika Amerika } \\
\text { untuk pertama kalinya mengalami depresi ekonomi (Banks, } 2005 \text {; Bosworth, } \\
2005 \text {; Colvin, } 1997 \text {; McShane \& William III, 2005). }\end{array}$ \\
\hline $\begin{array}{l}\text { California } \\
\text { Mens Colony, } \\
\text { San Luis } \\
\text { Obispo, } \\
\text { California }\end{array}$ & $\begin{array}{l}\text { Penjara pertama yang benar-benar didesain dengan memikirkan biaya } \\
\text { operasi penjara, (kemungkinan) overcrowding, filosofi perawatan rehabilitasi, } \\
\text { juga penjara pertama yang dinding penjaranya berwarna pastel untuk } \\
\text { menghindari warna kuno penjara, abu-abu. } \\
\text { Merupakan salah satu institusi di California Departement of Correction and }\end{array}$ \\
\hline
\end{tabular}




\begin{tabular}{|c|c|}
\hline Penjara & Penjelasan \\
\hline (1954). & $\begin{array}{l}\text { Rehabilitation yang memberikan program hospice (perawatan yang } \\
\text { berhubungan dengan kondisi emosi dan spiritual penderitanya) kepada } \\
\text { napinya. (Bosworth, } 2005 \text {; McShane \& Williams, 2005). }\end{array}$ \\
\hline $\begin{array}{l}\text { United States } \\
\text { Penitentiary, } \\
\text { Marion (1964) }\end{array}$ & $\begin{array}{l}\text { Semacam pengganti Alcatraz, merupakan penjara maksimum security } \\
\text { pertama di AS. Desain layout USP Marion merupakan bangunan blok-blok sel } \\
\text { yang saling terpisah, tetapi saling dihubungkan melalui lorong dan selalu } \\
\text { melewati pengawas. Desain site ini tidak menggambarkan layout desain tiang } \\
\text { telepon ataupun kampus, tapi layout interior nya memberikan ciri desain } \\
\text { radial. Bisa dikatakan bahwa institusi yang sangat menekankan pengawasan } \\
\text { (berdasarkan banyaknya "pengawas" yang dilalui untuk berpindah blok), } \\
\text { benar-benar menekankan bahwa tempat ini adalah supermax. } \\
\text { Napi pertama kali ditaruh di blok dengan pengawasan ketat. Napi } \\
\text { diharuskan bekerja di pabrik. Disediakan program pendidikan dan pelatihan } \\
\text { kerja. } \\
\text { Disebut sebagai cetak biru terbaik penjara supermax (McShane \& } \\
\text { Williams, 2005). }\end{array}$ \\
\hline $\begin{array}{l}\text { Minnesota } \\
\text { Correctional } \\
\text { Facility (1982). }\end{array}$ & $\begin{array}{l}\text { Satu-satunya penjara maksimum security di Minnesota, salah satu prototype } \\
\text { awal penjara generasi baru. (Bosworth, } 2005 \text {; McShane \& Williams, 2005). } \\
\text { Desain melingkar ala kampus yang dimodif dengan delapan unit yang lalu } \\
\text { menjadi } 9 \text { unit di tahun, tiap unit dihubungkan oleh } 2 \text { koridor pengaman, satu } \\
\text { untuk napi dan satu untuk staf. Blok sel tempat napi dipenjara juga terpisah } \\
\text { dengan bangunan administrasi utama untuk memastikan kalaupun terjadi } \\
\text { kerusuhan di blok tahanan (yang bisa langsung ditutup), maka kerusuhan tidak } \\
\text { dengan cepat meluas. Setelah "dinding" batas penjara yang berupa perbedan } \\
\text { elevasi tanah (karena secara teknis maka OPH ini berada di bawah tanah), } \\
\text { kompleks ini masih dikelilingi lagi oleh jalan beraspal tempat petugas } \\
\text { melakukan patroli, dan pagar kawat baja yang merupakan ciri khas penjara. }\end{array}$ \\
\hline & $\begin{array}{l}\text { Penjara sudah merupakan hukuman. Napi ditawari berbagai variasi program } \\
\text { sebagai usaha merehabilitasi mereka. }\end{array}$ \\
\hline $\begin{array}{l}\text { Administrative } \\
\text { Maximum } \\
\text { Security, } \\
\text { Florence } \\
\text { (1994). }\end{array}$ & $\begin{array}{l}\text { Kompleks Florence menjadi penjara supermax yang statusnya tetap } \\
\text { bertahan sebagai supermax hingga sekarang 2014. Kompleks penjara } \\
\text { supermax lain sebelum Florence sudah ditutup, atau diturunkan derajat tingkat } \\
\text { pengamanannya. Ia juga merupakan penjara pertama yang didesain hanya } \\
\text { untuk menampung napi yang memerlukan tingkat keamanan tinggi, terdiri } \\
\text { dari } 9 \text { blok unit terpisah, dengan daya tampung } 490 \text { napi, dan masing-masing } \\
\text { memiliki sel sendiri. Sebutan "Alcatraz Baru" yang sebelumnya melekat di } \\
\text { USP Marion, kini diambil alih oleh ADX Florence (Bosworth, 2005). } \\
\text { Pelaksanaan hukuman pada penjara ini, adalah dengan mengurung napi di } \\
\text { sel selama } 23 \text { jam sehari, diawasi dengan video kamera dan sensor suara, } \\
\text { sehingga sel yang ada didesain untuk menunjanghal tersebut. }\end{array}$ \\
\hline
\end{tabular}




\begin{tabular}{|l|l|}
\hline \multicolumn{1}{|c|}{ Penjara } & \multicolumn{2}{|c|}{ Penjelasan } \\
\hline $\begin{array}{l}\text { North Branch } \\
\text { Correctional } \\
\text { Institution, } \\
\text { Maryland (2003 } \\
\text { ). }\end{array}$ & $\begin{array}{l}\text { Didesain menutupi berbagai kelemahan penjara sebelumnya. Konsep } \\
\text { pengawasan menggunakan berbagai teknologi, dan pengamanan dengan } \\
\text { berbagai material terbaru sangat ditekankan. }\end{array}$ \\
& $\begin{array}{l}\text { Pendidikan terhadap para napi sangat ditekankan, sehingga terdapat } \\
\text { berbagai workshop maupun berbagai penunjang lain untuk memenuhi hal } \\
\text { tersebut. }\end{array}$ \\
\hline
\end{tabular}

\section{PEMBAHASAN}

Tiap penjara memiliki desainnya sendiri dalam aspek pengamanan yang terkanduing didalamnya. Pada masa Romawi hingga penjara-kastil, tujuan utamanya mengurung napi agar tidak kabur, sedangkan pelaksanaan hukumannya dilakukan di tempat lain. Di Walnut Street Jail, desain penjaranya dibuat menyatu dengan sekitar karena mencerminkan kepercayaan Quaker tentang kemanusiaan, sehingga segi pengamanan sedikit terabaikan. Pada Newgate Prison mulai terdapat upaya pemisahan blok sel. Lalu memasuki Eastern State Penitentiary yang berusaha menggabungkan konsep manusiawi dan disiplin diri, dengan tetap diawasi dengan ketat.
Memasuki desain "penjara baru", upaya reintegrasi dibawah pengawasan lebih ditekankan pada semua penjara yang ada, apapun tingkat keamanannya. Yang membedakan adalah tingkat pengawasan dan proses rehabilitasinya. Dimana penjara seperti CMC, USP Marion, OPH Minnesota dan NBCI didesain agar napi langsung mendapat rehabilitasi via disiplin diri, tetapi pada ADX Florence napi di isolasi dulu sebelum didisiplinkan. Untuk mencapai semua itu, maka penjara didesain agar semanusiawi mungkin dan memperhatikan segala aspek dalam memenuhi kebutuhan manusia, tentu dengan tingkat "manusiawi" yang berbeda-beda sesuai tingkat keamanan penjaranya.

Tabel 2. Aspek Desain Penjara.

\begin{tabular}{|c|c|c|c|c|c|}
\hline Penjara & Deter & Detect & Delay & Halt & Minimize \\
\hline Sekolah Gladiator & $\mathrm{O}$ & $\mathrm{O}$ & $\mathrm{X}$ & $\mathrm{X}$ & $\mathrm{X}$ \\
\hline Kastil & $\mathrm{O}$ & $\mathrm{O}$ & $\mathrm{O}$ & $\mathrm{O}$ & $\mathrm{O}$ \\
\hline Walnut Street Jail & $\mathrm{O}$ & $\mathrm{X}$ & $\mathrm{X}$ & $\mathrm{X}$ & $\mathrm{X}$ \\
\hline Newgate Prison & $\mathrm{O}$ & $\mathrm{O}$ & $\mathrm{O}$ & $\mathrm{O}$ & $\mathrm{X}$ \\
\hline Eastern State P. & $\mathrm{O}$ & $\mathrm{O}$ & $\mathrm{O}$ & $\mathrm{O}$ & $\mathrm{X}$ \\
\hline California M.C. & $\mathrm{O}$ & $\mathrm{O}$ & $\mathrm{X}$ & $\mathrm{X}$ & $\mathrm{O}$ \\
\hline USP Marion & $\mathrm{O}$ & $\mathrm{O}$ & $\mathrm{O}$ & $\mathrm{O}$ & $\mathrm{O}$ \\
\hline OPH Minnesota & $\mathrm{O}$ & $\mathrm{O}$ & $\mathrm{O}$ & $\mathrm{O}$ & $\mathrm{O}$ \\
\hline ADX Florence & $\mathrm{O}$ & $\mathrm{O}$ & $\mathrm{O}$ & $\mathrm{O}$ & $\mathrm{O}$ \\
\hline NBCI Maryland & $\mathrm{O}$ & $\mathrm{O}$ & $\mathrm{O}$ & $\mathrm{O}$ & $\mathrm{O}$ \\
\hline
\end{tabular}

Ket $: \mathrm{O}=$ Ada $; \mathrm{X}=$ Tidak ada

Walau didesain untuk mengurung sebelum dieksekusi, pada jaman Romawi penghukuman yang ada sudah memiliki niat untuk reintegrasi ke masyarakat Romawi, dengan sudut pandang 
mereka sendiri. Sedangkan pada penjara-kastil, kesempatan reintegrasi tidak pernah ada. Pada Walnut Street Jail dan Newgate Prison juga berupaya agar napi bisa kembali ke masyarakat. Hanya saja dalam kasus Walnut Street Jail terjadi UU baru yang membuatnya overcrowded, sedang pada Newgate Prison, dari awal memang terjadi salah desain sehingga keduanya gagal dalam melaksanakan penghukuman. Pada kasus ESP, walau bagus konsepnya diatas kertas, tapi realisasinya kurang matang sehingga pelaksaan penghukuman yang diharapkan pun gagal.
Desain pada era penjara baru sangat menekankan pengawasan, dan fasilitas yang dimanusiawikan. Tujuan utamanya tentu agar napi sadar bahwa dia terus diawasi, sehingga ia dipaksa untuk tidak punya pikiran lain selain agar fokus terhadap program-program rehablitasi yang diberikan kepadanya. Dan karena fasilitas yang ada disekitar mendukung, maka napi pun bisa menyesuaikan dirinya terhadap program rehabilitasi-reintegrasi yang diberikan, dan mempertinggi rasio keberhasilan

Tabel 3. Pengaruhnya terhadap Pelaksanaan Penghukuman

\begin{tabular}{|l|c|c|c|c|}
\hline \multicolumn{1}{|c|}{ Penjara } & Retributif & $\begin{array}{c}\text { Penggentar } \\
\text { Jeraan }\end{array}$ & Inkapasipasi & $\begin{array}{c}\text { Rehabilitasi- } \\
\text { Reintegrasi }\end{array}$ \\
\hline Sekolah Gladiator & $\mathrm{O}$ & $\mathrm{O}$ & $\mathrm{O}$ & $\mathrm{O}$ \\
\hline Kastil & $\mathrm{O}$ & $\mathrm{O}$ & $\mathrm{O}$ & $\mathrm{O}$ \\
\hline Walnut Street Jail & $\mathrm{O}$ & $\mathrm{O}$ & $\mathrm{O}$ & $\mathrm{O}$ \\
\hline Newgate Prison & $\mathrm{O}$ & $\mathrm{O}$ & $\mathrm{O}$ & $\mathrm{O}$ \\
\hline Eastern State P. & $\mathrm{O}$ & $\mathrm{O}$ & $\mathrm{O}$ & $\mathrm{O}$ \\
\hline California M.C. & $\mathrm{X}$ & $\mathrm{X}$ & $\mathrm{O}$ & $\mathrm{O}$ \\
\hline USP Marion & $\mathrm{X}$ & $\mathrm{O}$ & $\mathrm{O}$ & $\mathrm{O}$ \\
\hline OPH Minnesota & $\mathrm{X}$ & $\mathrm{O}$ & $\mathrm{O}$ & $\mathrm{O}$ \\
\hline ADX Florence & $\mathrm{O}$ & $\mathrm{X}$ & $\mathrm{O}$ & $\mathrm{O}$ \\
\hline NBCI Maryland & & $\mathrm{O}$ & $\mathrm{O}$ & $\mathrm{O}$ \\
\hline
\end{tabular}

$\mathrm{O}=$ Ada $; \mathrm{X}=$ Tidak ada 


\section{KESIMPULAN}

Prinsip desain penjara pada dasarnya bisa diformulasikan secara spesifik berdasarkan karakteristik penjara itu sendiri. Penjara berkeamanan maksimal, tentu akan dibuat di wilayah terpencil antah-berantah dilindungi kondisi geografis sebagai dinding penjara alami dengan tembok raksasa dan berbagai menara pengawas bersenjatakan senapan mesin dan sebagainya. Sedangkan penjara berkeamanan rendah, atau correctional facility akan dibangun di wilayah pemukiman penduduk untuk memanusiawikan para napinya.

Karena hal yang yang pasti dimiliki oleh napi secara berlebih adalah waktu, maka sebenarnya kalau waktu berlimpah yang mereka punya tidak dimanfaatkan, sama saja menambah jumlah pengangguran tak kentara di negara tersebut. Karena itulah penjara didesain agar waktu yang berlimpah itu bisa disalurkan untuk kegiatan yang produktif, dengan keberadaan akomodasi yang layak. Akomodasi itu bisa berupa pemenuhan untuk kebutuhan hidup sehari-hari, fasilitas-fasilitas untuk memperoleh pendidikan, keterampilan, bahkan layanan secara psikologis. Tapi hal tersbeut tentunya disesuaikan dengan batasan minimum dan sesuai tujuan, sehingga terkadang diperlukan bahan-bahan material yang khusus untuk realisasinya.

\section{SARAN}

Pada dasarnya, dalam membuat bangunan arsitektur ada 3 hal yang harus diperhatikan yaitu : iklim, budaya dan hukum nya. Iklim misalnya, tentu ada perbedaan membuat bangunan untuk wilayah Amerika dengan 4 musim dibanding Indonesia yang hanya 2 musim. Di negara dengan 4 musim yang memiliki musim dingin, maka di penjara akan diberikan heater (penghangat ruangan). Hal tersebut bukan untuk bermewah-mewahan, tetapi karena masalah kebutuhan. Sebab kalau tidak ada heater, akan menjadi beku para napi yang ada. Tapi jika langsung dijiplak menaruh heater di Indonesia yang mempunyai kelembapan tinggi, yang ada para napi akan memperoleh sauna. Karenanya, untuk negara seperti Indonesia diperlukan adanya bukaan jendela (dengan terali tentunya)untuk pertukaran udara. Jika hal tersebut sulit dilakukan (misal karena masalah lahan), maka bisa menggunakan exhaust fan untuk memperlancar pertukaran udara. Tentunya exhaust fan yang dipasang akan memiliki perberbedaan dengan yang dijual di pasaran karena benda tersebut akan dipasang di bangunan penjara. Begitupula rasio lahan dengan bangunan untuk pertukaran udara alami, maka jika merujuk studi oleh Ir. Purwo Ardoko, rasionya adalah $60 \%$ bangunan dengan $40 \%$ ruang terbuka (minimal).

Untuk contoh masalah budaya.Karena masyarakat Indonesia bersifat plural, maka sel penjara nya pun dirancang untuk diisi oleh 3,5 atau 7 orang. Olehkarenanya maka diperlukan ukuran sel dengan data ergonomi yang berbeda dengan sel di negara yang bersifat individu, dimana 1 sel untuk 1 orang, atau kadang 2 orang. Dari sisi hukum, bisa dilihat bagaimana di Amerika mengklasifikasikan penjara berdasarkan tingkat pengamanannya, yaitu minimum hingga super maksimum.

Pengklasifikasian tersebut berdampak pada desain akan penjara itu sendiri, sehingga akan ada desain penjara untuk keamanan tingkat minimum, dan ada pula desain penjara untuk keamanan di tingkat maksimum. Tetapi di Indonesia, pengklasifikasian penjara (lapas) 
dilakukan berdasarkan tingkat kelas (I III), walau tidak ada pembedaan desain berdasarkan kelas penjara itu sendiri, kecuali lapas terbuka (yang bisa disetarakandengan minimum security) atau tertutup.

\section{DAFTAR REFRENSI}

\section{Buku:}

Banks, Cindy. (2005). Punishment in America : a Reference Handbook,

ABC-CLIO, Santa Barbara, USA. ISBN 185109-681-7

Bosworth, Marry. (Ed). (2005). Encylopedia of Prison and CorrectionalFacilities (Vol 1-2), Sage Publication, Thousand Oaks.

Bozovic, Miran. (Ed). (1995). Jeremy Bentham The Panopticon Writings, Verso, London. ISBN 185984958

Burns, Tom. (Ed). (1992). Erving Goofman, Routledge, London. ISBN 0-20320550-2

Colvin, Mark. (1997). Penitentiaries, Reformatories, and Chain Gangs : Social Theoriy and the History of Punishment in Nineteenth-Century America, St. Martins Press, New York. ISBN 0-312-22128-2

Fields, Nic. (2009). Spartacus and the Slave War 73-71 BC:A Gladiator Rebels Againts Rome, Osprey Publishing, New York. ISBN: 978184908081

Hale, Jonathan A.( 2000 ). Building Idea : An Introduction to Architectural

Theory, John Wiley \& Son, Chichester, England. ISBN 0-471-85194-9

Harrison, Charles., \& Wood, Paul. ( Ed). (1992). Art in Theory 1900-1990 : An Anthology of Changing Ideas, Blackwell Publishers, Massachusetts. ISBN 0-631-16575-4

Hull. Lise E. (2006). Britain's Medieval Castle, Praeger Publishe, Westport.

Kepos, Paula. (Ed). (2008). Crime, Prisons and Jails, The Gale Group, Farmington Hills. ISBN-13: 978-1-4144-2948-9

Lepage, Jean Denis (2002). Castles and Fortified Cities of Medieval Europe,
McFarland \& Company, Jefferson.ISBN 0-7864-1092-2

Logan, Charles H. (1990). Private Prison : Cons and Pros, University Press, New York. ISBN 0-19-506353-8

McShane, Marilyn D., \& Williams, Frank R. III. (Ed). (2005). Encyclopedia of American Prison, Garland Publishing, New York. ISBN 0-20300937-1

Muchou Poo. (2005). Enemies of Civilization Attitudes toward Foreigners in Ancient Mesopotamia, Egypt, and China, Sunny Press, New York. ISBN 0-79 $\square 4-6363$

National Crime Prevention Institute. (2001). Understanding Crime Prevention (2nd Edition), ButterworthHeinemann, Woburn.ISBN 0-75067220

Neufert, Ernst. (1996). Data Arsitek Edisi 33, Jilid 1-2 (Sunarto Tjahjadi, Penerjemah), Erlangga, Jakarta

Norberg-Schulz, Christian. (198 ). Genius Loci : Toward Phenomenology of Achitecture, Rizzoli, New York.

Nossov, Konstantin. (2009). Gladiator : Rome's Bloody Spectacle, Osprey Publishing, New York.. ISBN: 9781846034 725

Panero, Julius., \& Zelnik, Martin (2003). Dimensi Manusia dan Ruang Interior. (Djoeliana Kurniawan, Penerjemah), Erlangga, Jakarta

Phillips, Todd S., \& Griebel, Michael A. (2003). Building Type Basics for Justice Facilities, John Willey \& Sons, New Jersey. ISBN : 0-471-00844-3

Rhodes, Lorna A. (2004). Total Confinement : Madness and Reason in the Maximum Security Prison, University of California Press, Los Angeles. ISBN 0-520-22987-8

Stokstad, Marilyn. (2009). Medieval Castle, Greenwood Press, Westport.

Sujatno, Adi. (2008). Pencerahan di Balik Penjara : Dari Sangkar Menuju Sanggar untuk Membangun Manusia Mandiri, Teraju, Jakarta. ISBN : 978 $-979-3603-92-6$ 
Wisdom, Stephen. (2001). Gladiators 100 BC$A D$ 200, Osprey Publishing, Oxford. ISBN 1841762997

\section{Seminar}

Ardoko, Purwo. (2014, Juni). Pokok-pokok Pedoman Pemikiran dalam Rancang Bangun Bangunan UPT Pemasyarakatan (Lapas / Rutan / Bapas / Rupbasan). Dipresentasikan dalam seminar Keamanan Penjara, Jakarta

\section{Jurnal}

Gill, Howard B. (2013, Mei 25). Correctional Philosophy and Architecture. The
Journal of Law, Criminology, and Police Science, Vol. 53, No. 3 (Sep., 1962), pp 312-322. http://www/jstor.org/stable/114146 6

Morris, Robert G. \& Worral, John L. (2010, November 09). Prison Architecture and Inmate Misconduct: A Multilevel Assessment. Crime \& Delinquency $\begin{array}{llllll}X X & (X) & 1-27 & \text { (C) } & 2010 & \text { SAGE }\end{array}$ Publications, $\quad$ DOI: 10.1177/0011128710386204.http://c ad.sagepub.com/content /early/2010/11/05/ 0011128710386204 